\title{
Spectrophotometric Estimation of Gemcitabine HCl in Pharmaceutical Dosage form via Oxidative Coupling Reaction
}

\author{
MALLADI SRINIVAS REDDY* and SADIYA FIRADOUS \\ Department of Pharmaceutical Analysis \& Quality Assurance, Vaageswari College of \\ Pharmacy, Karimnagar, TS (505481), India \\ msr.srinivas@gmail.com
}

Received 23 July 2015 / Accepted 1 August 2015

\begin{abstract}
Gemcitabine $\mathrm{HCl}$ is an antiviral drug, novel, facile, sensitive and selective spectrophotometric method have been developed for the quantitative estimation of gemcitabine $\mathrm{HCl}$ in pharmaceutical formulations with coupling reagent. The proposed method involves the oxidative coupling reaction of gemcitabine $\mathrm{HCl}$ with 3-methyl-2-benzothiazolinone hydrazone hydrochloride monohydrate in the presence of ferric chloride and acidic medium to form bluish green colored chromogen at $558 \mathrm{~nm}$. There is no interference observed from the excipients that are present in the Gemcitabine $\mathrm{HCl}$ pharmaceutical dosage form with this estimation. The optimum reaction conditions and other important analytical parameters were established.
\end{abstract}

Keywords: Gemcitabine HCl, 3-Methyl 1, 2-Benzothiazolinehy-drazone hydrochloride, UV-Visible spectrophotometry

\section{Introduction}

Gemcitabine $\mathrm{HCl}$ (GTHC) is chemically know as 2'-deoxy-2', 2'-difluorocytidine monohydrochloride is a pyrimidine analog that is proven to be active against a variety of solid tumors. It is widely used in the treatment of cancers of pancreas, lung, breast, bladder, kidney and biliary tract either singly or in combination with other cytotoxic agents ${ }^{1}$. It is being investigated for use in esophageal cancer and is used experimentally in lymphomas and various other tumors ${ }^{2}$. It is a pro-drug and once transported into the cell, must be phosphorylated by deoxycytidine kinase to an active form and inhibit processes required for DNA synthesis.

Incorporation of gemcitabine diphosphate into DNA is most likely the major mechanism by which gemcitabine causes cell death ${ }^{3}$. 3-Methylbenzthiazolinone-2-hydrazone is an electrophillic coupling reagent employed earlier in the quantification of aromatic amines and hetero aromatic compounds ${ }^{4}$. Later, this was extended for the determination of a large number of organic compounds including those containing methylene groups, carbonyl groups, sacharrides, steroids, olefins, phenols, Schiff's base, aromatic hydrocarbons, furfural 
and heterocyclic bases ${ }^{5}$, MBTH (3-Methyl 1, 2-Benzothiazolinehy-drazone hydrochloride) is also used in the analysis of several compounds of biochemical ${ }^{6}$, pharmaceutical ${ }^{7}$ and insecticidal $^{8}$. MBTH responds to the enzymatic activity of some of the enzymes like peroxidase $^{9}$, lactase ${ }^{10}$ alcohol oxidase ${ }^{11}$ and toluene-4-monooxygenase ${ }^{12}$ in the presence of corresponding substrates. The present study documents an accurate, sensitive, rapid, selective and reproducible visible spectrophotometric assay which meets an accepted analytical validation. Spectrophotometry is the technique of choice even today in the laboratories of research, hospitals and pharmaceutical industries due to its low cost and inherent simplicity.

\section{Experimental}

Analytical technologies spectro2060 plus UV Visible spectrophotometer with $1 \mathrm{~cm}$ matched quartz cells, Shimadzu ATX224 Electronic balance and Bio-Technics india electronic water bath were used. All chemicals and reagents were of analytical grade and water was always double distilled water. Gemcite $\mathrm{HCl}$ was received from Dr.Reddy's laboratories Ltd, Hyderabad, Marketed injection formulation (Gemcite) manufactured by Eli lilly pharma Ltd was purchased from market.

\section{Materials and methods}

$1 \mathrm{~g}$ of $\mathrm{MBTH}(1 \% \mathrm{w} / \mathrm{v})$ and $\mathrm{FeCl}_{3}(1 \% \mathrm{w} / \mathrm{v})$, respectively in distilled water and diluted to $100 \mathrm{~mL}$. Standard stock solution for Gemcitabine $\mathrm{HCl}(\mathrm{GTHC})(1000 \mu \mathrm{g} / \mathrm{mL})$ was prepared by dissolving $100 \mathrm{mg}$ of GTHC in distilled water and diluted to $100 \mathrm{~mL}$.

A series of different aliquots of GTHC standard (0.1-1 mL) were transferred into a different $10 \mathrm{~mL}$ volumetric flasks to each one of these flasks $1 \mathrm{~mL}$ of $1 \% \mathrm{w} / \mathrm{v}$ MBTH reagent followed by $1 \mathrm{~mL}$ of $1 \% \mathrm{w} / \mathrm{v} \mathrm{FeCl} 3$ were added. The volume was made up to $10 \mathrm{~mL}$ with water and swirled thoroughly. The absorbance of bluish-green colored complex was measured at $558 \mathrm{~nm}$ making zero absorbance with reagent blank. The calibration curve was plotted by recommended method as shown in Figure 1.

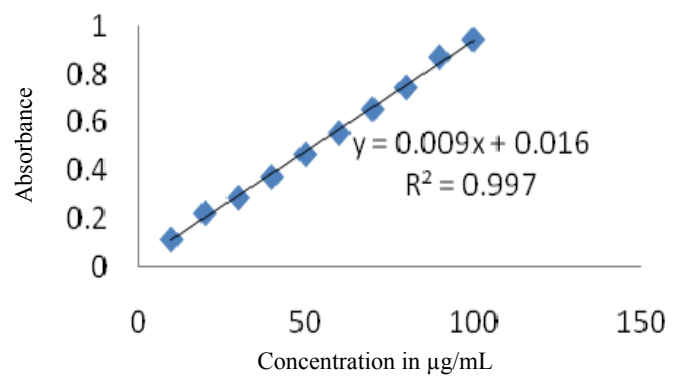

Figure 1. Calibration curve of GTHC

\section{Absorption spectra}

The formation of bluish green colored complex was employed in the quantitative detection of GTHC with MBTH in presence of ferric chloride. However when MBTH was initially mixed with GTHC and then with oxidizing agent, a bluish green colored compound was produced with maximum absorbance in the visible range at $558 \mathrm{~nm}$ and shown in Figure 2. MBTH loses two electrons and one proton due to oxidation with $\mathrm{Fe}$ (II), forming an electrophilic intermediate, which is the active coupling species. The electrophilic intermediate and the analyte under goes electrophilic reaction with the formation of colored product Figure 3. 


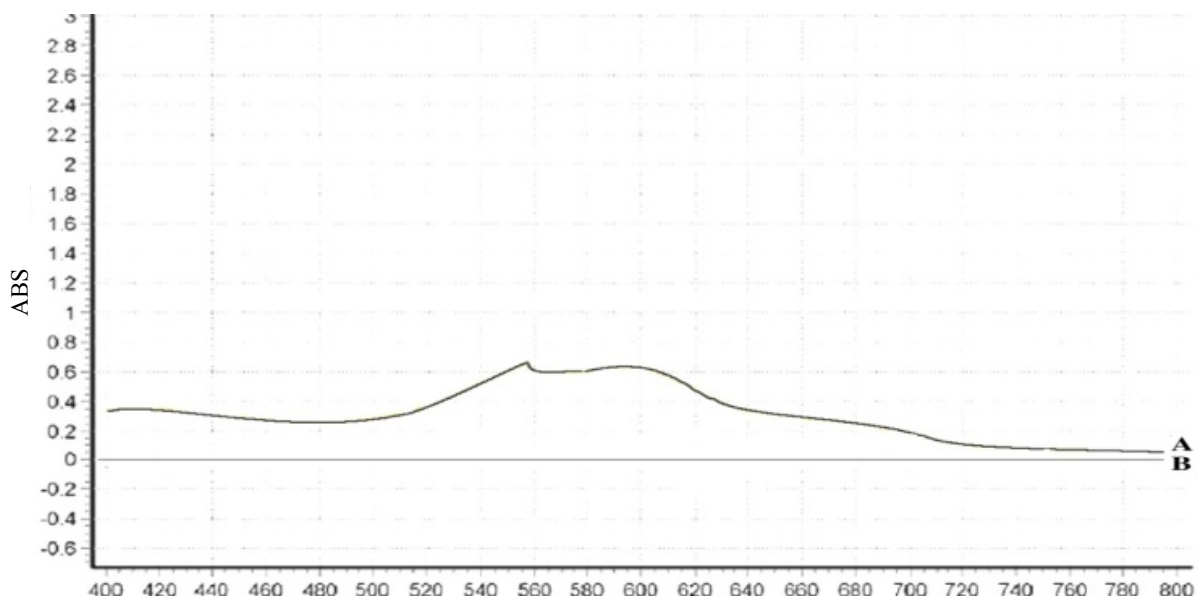

Figure 2. Absorption spectra of GTHC with MBTH $\mathbf{A}=$ Absorbance Peak $\mathbf{B}=$ Baseline Peak<smiles>Cn1/c(=N/N)sc2ccccc21</smiles><smiles>Cn1/c(=N/[NH-])sc2ccccc21</smiles>

MBTH<smiles>CN1c2ccccc2SC1N=NNc1ccn(C2(F)OC(CO)C(O)C2(F)F)c(=O)n1</smiles>

Bluish-Green colored complex

Figure 3. Scheme for the reaction pathway of GTHC with MBTH

Table 1. Optical and regression characteristics of the proposed method

\begin{tabular}{cc}
\hline Parameter & Gemcitabine \\
\hline$\lambda_{\max }, \mathrm{nm}$ & 558 \\
Beer's law limit, $\mu \mathrm{g} \mathrm{mL} \mathrm{mL}^{-1}$ & $10-100, \mu \mathrm{g} \mathrm{mL}^{-1}$ \\
Regression equation $(\mathrm{Y}=\mathrm{mX}+\mathrm{C})$ & $\mathrm{Y}=0.009 \mathrm{X}+0.016$ \\
Slope & 0.009 \\
Intercept & 0.016 \\
Correlation coefficient $\left(\mathrm{r}^{2}\right)$ & 0.997 \\
\% Recovery & $98.47-101.13$ \\
Color & Bluish green \\
LOD, $\mu \mathrm{g} \mathrm{mL} \mathrm{mL}^{-1}$ & $0.297, \mu \mathrm{gL}^{-1}$ \\
LOQ, $\mu \mathrm{g} \mathrm{mL} \mathrm{mL}^{-1}$ & $0.90, \mu \mathrm{g} \mathrm{mL}^{-1}$ \\
\hline
\end{tabular}


Method validation ${ }^{13-16}$

\section{Linearity}

The calibration curve for GTHC was prepared and linear relationship between concentrations versus absorbance was observed by obeying Beer's law in the concentration range of $10-100 \mu \mathrm{g} / \mathrm{mL}$ and good correlation coefficient of 0.997 was found.

\section{Accuracy}

The accuracy of the proposed method was determined by standard addition method, which involved the addition of different concentrations of pure drug to a known preanalyzed formulation sample and the total concentration was determined using the proposed method. The percent recovery was found to be $98.47 \%-101.13 \%$.

\section{Precision}

The precision of the method was determined by analysis of 6 replicates of the working standards at two concentrations. At these two concentrations intra and inter day precision studies were performed for three consecutive days. Relative standard deviation was found to be $0.57,0.45$ and $0.55,0.81$ respectively.

\section{Sensitivity}

The sensitivity of the proposed method was determined by calculating LOD \& LOQ for GTHC using calibration standards. LOD and LOQ was found to be $0.297\left(\mu \mathrm{g} \mathrm{mL}^{-1}\right)$ and $0.90\left(\mu \mathrm{g} \mathrm{mL}^{-1}\right)$ respectively.

\section{Robustness}

The robustness of the proposed method was examined by evaluating the influence of a small variation of the method variables including the wavelength and volume of the reagent. The results were found to be satisfactory i.e $<2 \%$.

\section{Assay}

For analysis of pharmaceutical formulation, an accurate quantity of the powder equivalent to $1 \mathrm{mg}$ of GTHC was weighed and transferred into $10 \mathrm{~mL}$ volumetric flask. $5 \mathrm{~mL}$ of distilled water was added to dissolve the contents of the flask and made up to $10 \mathrm{~mL}$ with distilled water which ensures the final concentration of $100 \mu \mathrm{g} / \mathrm{mL}$. The above solution was filtered using Whatmann filter paper. From this solution, $1 \mathrm{~mL}$ aliquot was pipetted out in $10 \mathrm{~mL}$ volumetric flasks to which $1 \mathrm{~mL}$ of $1 \% \mathrm{w} / \mathrm{v}$ MBTH reagent was added and swirled the solution for 10 mins. Then $1 \mathrm{~mL}$ of $1 \% \mathrm{w} / \mathrm{v} \mathrm{FeCl}_{3}$ solution was added and swirled the solution for 10 mins. Then volume was diluted up to $10 \mathrm{~mL}$ with distilled water and the absorbance of the bluish-green colored complex was measured at $558 \mathrm{~nm}$ against a reagent blank, which was prepared similarly without drug. There was no interference from the excipient commonly present in the formulation. The GTHC content was found to be $98.56 \%$ with a $\%$ RSD of 0.74 respectively Table 2 . The validity of the proposed methods was further assessed by applying the standard addition technique.

Table 2. Assay of gemcitabine $\mathrm{HCl}$

\begin{tabular}{cccc}
\hline Brand name & $\begin{array}{c}\text { Label claim, } \\
\text { mg/vial }\end{array}$ & $\begin{array}{c}\text { Amount of drug } \\
\text { estimated, \% }\end{array}$ & Mean $^{\mathrm{a}} \%$ RSD \\
\hline Gemcite & 200 & 98.56 & 0.74 \\
\hline
\end{tabular}

$a$ - assay average of six determinations $(n-6)$ 


\section{Conclusion}

The present study described the successful evaluation of MBTH as an analytical reagent in the development of simple and rapid spectrophotometric method for the accurate determination of gemcitabine $\mathrm{HCl}$ in its dosage forms. The reagent utilized in the proposed method is eco-friendly, readily available and the procedure doesn't involve any critical reaction conditions or tedious sample preparation. Moreover, the method is free from interference by common additives and excipient. Hence method can be wide applicability in routine quality control was well established by the assay of Gemcitabine $\mathrm{HCl}$ in bulk and pharmaceutical formulation.

\section{Acknowledgment}

The authors are thankful to Dr. G. Srinivas Reddy, General Secretary, Vaageswari educational society, for providing facilities and infrastructure to carry out this project work.

\section{References}

1. $\quad$ Neil M J, The Merck Index $13^{\text {th }}$ Ed., 2001, 4397.

2. Plunkett W, Huang $\mathrm{P}, \mathrm{Xu}$ Y Z, Heinemann V, Grunewald R and Gandhi V, Oncology, 1995, 4(Suppl 11), 3-10.

3. Mini E, Nobili S, Caciagli B, Landini I and Mazzei T, Ann Oncol., 2006, 17(Suppl 5), 7-12.

4. $\quad$ Sawicki E, Stanley T W, Hauser T R, Elbert W and Noe J L, J Anal Chem., 1961, 33, $722-725$.

5. Anthon G E and Barrett D M, J Agr Food Chem., 2004, 52(12), 3749-3753; DOI:10.1021/jf035284w

6. Nagaraja P, Shivakumar A and Shrestha A K, Anal Biochem., 2009, 395(2), 231-236; DOI:10.1016/j.ab.2009.07.053

7. Ribeiro D S, Prior JA, Santos J L, Lopes J A and Lima J L, Talanta, 2009, 79(4), 1161-1168; DOI:10.1016/j.talanta.2009.02.052

8. Sastry C S and Vijaya D, Talanta, 1987, 34(3), 372-374; DOI:10.1016/00399140(87)80051-6

9. Abdullah J, Ahmad M, Heng LY, Karuppiah N and Sidek H, Anal Bioanal Chem., 2006, 386(5), 1285-1292; DOI:10.1007/s00216-006-0786-6

10. Jordaan J and Leukes W D, Enzym Microb Technol., 2003, 33(2-3), 212-219; DOI:10.1016/S0141-0229(03)00116-9

11. Sibirny V A, Gonchar M V, Grabek-Lejko D, Pavlishko H M, Csoregi E and Sibirny A A, Inter J Envi Anal Chem., 2008, 88(4), 289-301; DOI:10.1080/03067310701593615

12. Nolan L C and Connor K E O, Anal Biochem., 2005, 344(2), 224-231; DOI:10.1016/j.ab.2005.05.032

13. Sowjanya K, Thejaswini J C, Gurupadayya, B M and Indupriya M, Der Pharma Chem., 2011, 3(1), 112-122.

14. Prakash S S, Kalyan K, Rajuand S A, Danki L S, Res Phar Technol., 2012, 4, 951-954.

15. Prakash S S, Chakravarthy K and Purushothamrao K, J Anal Chem., 2011, 1(2), 19-24.

16. Thakkar H, Das S and Patel DA, Inventi Rapid: Pharm Analysis \& Qua Assurance, 2010, 1, 55 . 